\title{
'||-|||||||||||||||||||||||||||||||||||||||||||||||||||||||||||||||||||.
}

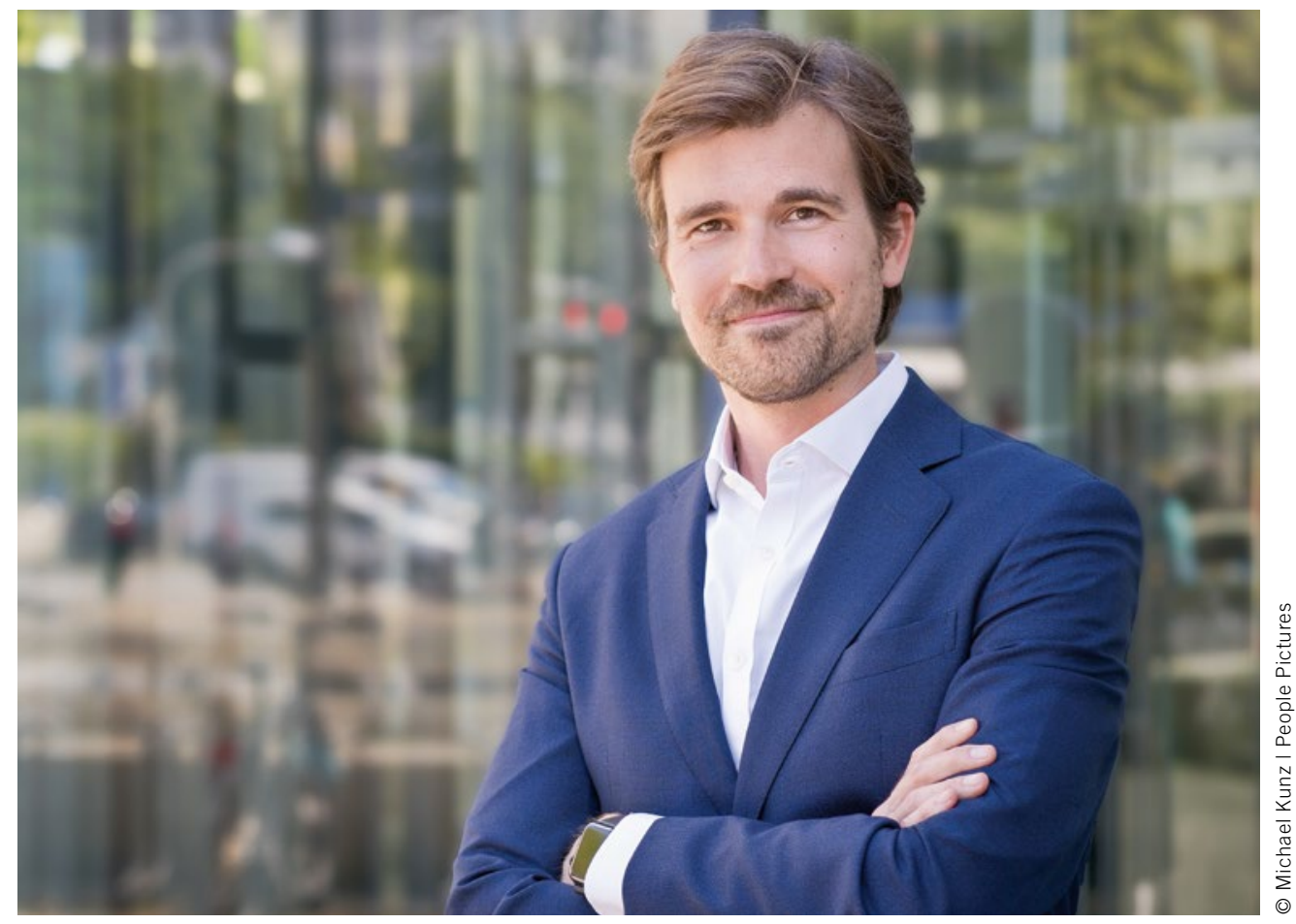

Dr. Philipp Seidel

Principal bei der Strategie- und Innovationsberatung Arthur D. Little

\section{Letzter Aufruf für Europas Automobilindustrie}

Die Covid-19-Krise bringt die Automobilindustrie in den „perfekten Sturm“. Der globale Pkw-Absatz wird 2020 um etwa $25 \%$ einbrechen und - je nach Quelle der Prognose bei nur noch 65 bis 70 Millionen Fahrzeugen liegen. In den nächsten drei Jahren werden voraussichtlich über 50 Millionen Fahrzeuge weniger verkauft werden als Anfang dieses Jahres geplant. Das stellt Automobilhersteller, Zulieferer und Händler vor riesige finanzielle und zum Teil existenzielle Herausforderungen.

Pandemie und Wirtschaftskrise treffen die Industrie in einer schon seit Jahren andauernden fundamentalen Transformation. Der Übergang zu elektrisch betriebenen, digitalisierten und vernetzten Fahrzeugen, aber auch zu neuen Nutzungs- und Besitzmodellen stellt fast alle bisherigen Denkund Arbeitsweisen, Strukturen und Glaubenssätze in den Unternehmen auf den Prüfstand. Lange hat die europäische Industrie diesen Wandel nicht ernst genug genommen.

Der Wandel wird durch die aktuelle Krise nicht gebremst, er wird sogar noch beschleunigt: Das Krisenjahr 2020 wird zum Jahr der Elektromobilität und „Peak Combustion Engine“, der Gipfel der Verkäufe von Fahrzeugen mit Verbrennungsmotoren, liegt hinter uns. Europäische Regierungen haben mit ihren Förderprogrammen und dem Festhalten an $\mathrm{CO}_{2}$-Zielen noch einmal klar gemacht, wohin die Reise geht. Kunden fragen wie nie zuvor elektrifizierte Fahrzeuge nach, und europäische Hersteller können kaum liefern. Digitale Vertriebsund Servicemodelle beweisen gerade ihre Funktionsfähigkeit und ihre positiven Effekte. Auto-Abos ermöglichen es in wirtschaftlich unsicheren Zeiten, die Nutzung flexibel an den eigenen Bedarf und die Möglichkeiten anzupassen und gewinnen an Attraktivität. Pilotprojekte reichen hier nicht mehr aus.

Auch die europäische Automobilindustrie arbeitet inzwischen mit Hochdruck daran, die Transformation zu meistern. Allerdings hat die Politik zu lange die schützende Hand über alte Erfolgsmodelle gehalten und den Innovationsdruck verringert. Zu lange wurde in Europa am „Tesla-Fighter“ getüftelt. Der wahre Tesla-Fighter ist aber kein Elektrofahrzeug, das sich durch Spaltmaße oder Beschleunigungswerte auszeichnet, sondern eine auf eine neue Normalität und nachhaltige Zukunft ausgerichtete Automobil- und Mobilitätsindustrie, in der klassische Branchengrenzen aufweichen. Dies erfordert neue Qualifikationen, neue Entwicklungsstrukturen, neue Fahrzeugkonzepte, neue Zulieferer- und Partnernetzwerke, neue Infrastrukturen und neue Prinzipien. Die aktuelle Krise erhöht den Druck weiter und wird zu schöpferischer Zerstörung im Sinne Schumpeters führen. Eine Bereinigung und veränderte Kraftverhältnisse sind nicht mehr aufzuhalten. Die europäische Autoindustrie ist innovationsstark und in vielen Bereichen führend, aber 2020 wird ihr Schicksalsjahr. Sie hat gerade den letzten Aufruf zur Transformation gehört. 